\begin{tabular}{|c|c|c|}
\hline & Int.J.Curr.Microbiol.App.Sci (2016) 5(5): 636-646 & \\
\hline & International Journal of Current Microbiology and Applied Sciences & 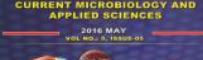 \\
\hline & ISSN: 2319-7706 Volume 5 Number 5 (2016) pp. 636-646 & \\
\hline EXCELLENT & ittp://www.1]cmas.com & \\
\hline
\end{tabular}

Original Research Article

http://dx.doi.org/10.20546/ijcmas.2016.505.064

\title{
In Vitro Antidermatophytic Study on Leaf Extracts of Azadirachta indica and Andrographis paniculata against Trichophyton Species
}

\author{
C. Banu Rekha ${ }^{1,2 *}$, G. Krishnaveni ${ }^{2}$, P. Rajendran ${ }^{3}$, Ramya Anandan ${ }^{2}$ and M.Elakkiya ${ }^{2}$ \\ ${ }^{1}$ Research Scholar, Bharathiyar University, Coimbatore, India \\ ${ }^{2}$ Department of Microbiology, Dr. MGR Janaki College of Arts \& Science for Women, Chennai \\ ${ }^{3}$ Department of Microbiology, Sri Ramachandra medical College \& Research Institute, Sri \\ Ramachandra University, Porur, Tamilnadu, India \\ *Corresponding author
}

\section{Keywords}

Dermatophytes,

Soil sample, Hair

baiting technique,

Antidermatophytic

activity,

Azadirachta

indica,

Andrographis

paniculata.

\section{Article Info}

Accepted:

20 April 2016

Available Online:

10 May 2016

\section{A B S T R A C T}

The study was to assess the antidermatophytic activity of the ethanol, ethyl acetate and aqueous extract of Neem (Azadirachta indica) and Nilavembu (Andrographis paniculata) leaves with ethanol, chloroform and aqueous extract against dermatophytes isolated from different soil. Dermatophytes were identified, Out of the 115 soil samples, 64 isolates of Trichophyton mentagrophytes, 42 isolates of Trichophyton rubrum, 24 isolates of Trichophyton tonsurans, 37 isolates of Trichophyton terrestre, 20 isolates of Trichophyton verrucosum were isolated and identified. We selected two most common pathogen among the Trichophyton species i.e., Trichophyton mentagrophytes and Trichophyton rubrum to find the antidermatophtitic activity of Plant extracts. The minimum inhibitory concentration (MIC) by broth dilution method and minimum fungicidal concentration (MFC) with the leaf extracts of the plants Azadirachta indica and Andrographis paniculata against the isolated dermatophytes was determined. Among the Trichophyton species, T.mentagrophytes was inhibited by ethanolic extract of Azadirachta indica leaves in the concentration of $62.5(\mu \mathrm{g} / \mathrm{ml})$, T.rubrum was inhibited by ethanolic extract in the concentration of $125(\mu \mathrm{g} / \mathrm{ml})$, Ethanolic extract was found to have higher inhibitory activity than the ethyl acetate and the aqueous extract against both the organism T.mentagrophytes and T.rubrum. T.mentagrophytes was inhibited by ethanolic extract of Andrographis paniculata leaves extract in the concentration of $125(\mu \mathrm{g} / \mathrm{ml})$, T.rubrum was inhibited by ethanolic extract in the concentration of $62.5(\mu \mathrm{g} / \mathrm{ml})$. Ethanolic extract found to have higher activity than the chloroform and the aqueous extract against both the organism T.mentagrophytes and T.rubrum. T.mentagrophytes and T.rubrum were inhibited by ethanolic extract of Azadirachta indica and Andrographis paniculata extract in the concentration of $62.5(\mu \mathrm{g} / \mathrm{ml})$, against T.mentagrophytes and $125(\mu \mathrm{g} / \mathrm{ml})$, against T.rubrum. Ethanolic extract with the combination of Azadirachta indica and Andrographis paniculata have greater inhibitory activity against T.mentagrophytes than T.rubrum when combined together due to the synergistic or additive effect of the phytocomponents. The results of this research gives us the therapeutic potential of Azadirachta indica and Andrographis paniculata to control the dermatophytosis. 


\section{Introduction}

Dermatophytes causes cutaneous mycoses and remains a public health problem. Dermatophytes require keratin for growth. Dermatophytes are a group of fungi that cause infections of skin, hair and nails. They include three genera namely Epidermophyton, Microsporum and Trichophyton. The majority of the fungi producing diseases in human beings and animals exist freely in nature as soil saprophytes.

Soil is considered as one of the most complex microbial habitats in which many fungi complete their life. Soil serves as a natural reservoir for both pathogenic and saprophytic fungi. Factors influencing the distribution of keratinophilic fungi have been relatively well recognized in the soil environment (Banu Rekha et al., 2015).

The use of plants and plant products as medicines could be traced as far back as the beginning of human civilization. The earliest mention of medicinal use of plants in Hindu culture is founds in "Rigveda", which is said to have been written between 4500 - 1600 B.C. and is supposed to be the oldest repository of human knowledge (Bishnu Joshi et al., 2011). Tamilnadu is one of the most botanized areas of South India. Plants produce a diverse range of bioactive molecules, making them rich source for the therapeutic efficacy. Plants are rich in a wide variety of secondary metabolites such as tannins, terpenoids, alkaloids, flavonoids, etc. which have been found to have medicinal properties.

Azadirachta indica is locally known as Neem (Mohammad et al., 2013). It is a tree in the mahogany family of Meliaceae. It is native to India, Bangladesh, Thailand, Nepal and Pakistan. Neem is most important medicinal plant that has been declared worldwide as the "Tree of the 21 st century" by the United Nations. In India, it is called "Divine Tree", "Life giving tree", "Nature's Drugstore", "Village Phar-macy" and "Panacea for all diseases" Traditionally, neem is also widely used in Indian Ayurvedic medicine system for the treatment of incurable diabetes (Hossain and Nagooru, 2011) Sanskrit name of the neem tree is 'Arishtha' meaning 'reliever of sickness' and hence is considered as 'Sarbaroganibarini'(Susmitha et al., 2013). The tree is still regarded as 'village dispensary' in India (Imam Hashmat 1 et al., 2012). It is a tree 40-50 feet or higher, with a straight trunk and long spreading branches forming a broad round crown, it has rough dark brown bark with wide longitudinal fissures separated by flat ridges. The leaves are compound, imparipinnate, each comprising 5-15 leaflets. The compound leaves are themselves alternating with one another. It bears many flowered panicles, mostly in the leaf axils. The seed are ovate and about one $\mathrm{cm}$ long with sweet scented white and glabrous, 12-20 mm long (Ross, 2001). Fruits are green, turning yellow on ripening, aromatic with garlic like odour. Fresh leaves and flowers come in MarchApril. Fruits mature between April and August depending upon locality. Chemical constituents contain many biologically active compounds that can be extracted from neem, including alkaloids, lavonoids, triterpenoids, phenolic compounds, carotenoids, steroids and ketones, biologically most active compound is azadirachtin, it is actually a mixture of seven isomeric compounds labelled as azadirachtin $\mathrm{A}-\mathrm{G}$ and azadirachtin $\mathrm{E}$ is more effective 1. The chemical constituents are found in the leaves of neem as nimbin, nimbanene, 6desacetylnimbinene, nimban-diol, nimbolide, ascorbic acid, n-hexacosanol and aminoacid, 7-desacetyl-7-benzoylazadira- 
dione, 7-desacetyl-7-benzoylgedunin, 17hydroxyazadiradione and nimbiol. Pharmacological actions are Abortifacient, analgesic, anthelminthic, antibacterial, antiyeast, antiulcer, antifertility, antifilarial, antifungal, antihyperglycemic, antiinflammatory, anti-viral, antimalarial, diuretic, antinematodal, antipyretic, antispasmodic, insecticidal, antispermatogenic, antitumor, hypercho-lesteremic, hypoglycaemic, immuno-modulator.

Andrographis paniculata (Burm. f.) Wall Ex Nees is an erect annual herb family Acanthaceae, commonly native of Southern Asia. Andrographis paniculata was recommended in Charaka Samhita dating to $175 \mathrm{BC}$ for treatment of jaundice along with other plants in multi plant preparations (Meenu sharma et al., 2012). Andrographis paniculata is available abundantly in south eastern Asia i.e., India, Sri Lanka, Pakistan and Indonesia. Tamilnadu, Karnataka, Maharashtra, Orissa, Uttar Pradesh and Uttarakhand. It is easily cultivated from seeds on all types of soil. It is bitter in taste. As an Ayurveda herb is also known as Kalmegh or Kalamegha, meaning "dark cloud". It is also known as Bhui-neem, meaning "neem of the ground. The genus Andrographis consists of 28 species of small annual shrubs essentially distributed in tropical Asia (Manoharan, 2013).

Andrographis paniculata carrying other meanings as well. Andro is a place name in India. In fact, Andro is a town in Imphal East district, Manipur state, North East of India. Andro also is a prefix in the Greek language meaning "male" or "masculine" can refer to a number of things. Graphis is a genus of lichens from the family Graphidaceae and in the Latin language means pencil, paintbrush or writing style, and paniculata performs a Latin pronunciation of paniculate or panicle, which refers to the inflorescence of the plant (2).

Andrographis paniculata grows erect to a height of $30-110 \mathrm{~cm}$ in moist, shady places. The slender stem is dark green, squared in cross-section with longitudinal furrows and wings along the angles. The lance-shaped leaves have hairless blades measuring up to 8 centimeters long by 2.5 wide. The small flowers are borne in spreading racemes. The fruit is a capsule around 2 centimeters long and a few millimeters wide. It contains many yellow-brown seeds. Phytochemistry its major chemical constituents present in the plant are flavanoids, phenolics. Andrographolide is the major constituent extracted from the leaves of the plant which is a bicyclic diterpenoid lactone. The major chemical constituents present in the plant are 14-Deoxy-11- dehydroandrographolide, 14Deoxy-11-oxoandrographolide, 5-Hydroxy7,8,2',3'-Tetramethoxyflavone, 5-Hydroxy 7,8,2' Trimethoxyflavone, Andrographine, Neoandrographolide, Panicoline, PaniculideA, Paniculide-B, Paniculide-C. Pharmacological actions are due to the Bitterness from this plant is related with its various pharmacological properties such as antibiotic, antiviral, antimicrobial, antiinflammatory, antivenom and immunostimmulatory, anticancer, anti-HIV, anti-allergic, and hypoglycemic activity. Also used for treating common cold, upper respiratory tract infection, tonsillitis, pharyngitis, laryngitis, pneumonia, tuberculosis, pyelonephritis, hepatic impairment. Also can be used as antityphoid and antimalarial since the whole plant is having medicinal value especially leaves which are in fresh and dried condition which are extensively included in the Asian traditional medicine for treating illness (Rajpar et al., 2011).

Most of the drugs today are obtained from 
natural sources or semi synthetic derivatives of natural products used in the traditional systems of medicine (Sukanya et al., 2009). The drugs already in use to treat infectious disease are of concern because drug safety remains an enormous global issue. Most of the synthetic drugs cause side effects and also most of the microbes developed resistant against the synthetic drugs (Chanda et al., 2011). To alleviate this problem, antimicrobial compounds from potential plants should be explored. These drugs from plants are less toxic, side effects are scanty and also cost effective. It increases the interest on traditional ethnomedicine may lead to discovery of novel therapeutic agent.

\section{Materials and Methods}

\section{Sources of Dermatophytes}

Dermatophytes were isolated from the Soil samples. Soil samples were inoculated on to SDA by spread plate technique, SDA with chloramphenicol to minimize bacterial contamination and cycloheximide to reduce the contamination of saprophytic fungi, plates were incubated at $30 \mathrm{oC}$ - room temperature for 21 days.

\section{Isolation and Identification}

The Macroscopic appearance of the dermatophytes after incubation in different media were studied which includes colour, texture, reverse pigmentation etc., The Microscopic observation of the dermatophytes are studied by wet mount technique which includes potassium hydroxide - $\mathrm{KOH}$ and Lactophenol cotton blue - LPCB Mount.

Microscopic appearance of shape, size, arrangement and texture of Macroconidia, Microcondia, hyphae and spores were observed.
Hair baiting technique is also done to isolate the dermatophytes from soil. Trichophyton Species were isolated from the soil samples they are Trichophyton mentagrophytes, Trichophyton rubrum, Trichophyton tonsurans, Trichophyton terrestre and Trichophyton verrucosum.

\section{Plant Sample}

Leaves of Azadirachta indica and Andrographis paniculata were collected from Chennai, Tamilnadu. Healthy and uninfected leaves were identified and selected. The collected leaves were packed instantly in polyethylene bags. The samples were kept frozen at $4 \circ \mathrm{C}$ until extraction. The samples were washed with water and finally with distilled water to remove the dust and debris. The samples were dried under shade at room temperature for 3 days. Finally the dry leaves samples were pulverized into powdered form.

\section{Preparation of Plant Extracts}

\section{Neem- Azadirachta indica}

The leaves of Azadirachta indica were dried at room temperature and then crushed into a coarse powder using a blender. Powdered leaves were suspended in petroleum ether and kept in refrigerator overnight to remove fatty substances. After incubation the supernatant was discarded and the residue was dried at room temperature.

The residue was further divided into three parts and 25 grams each was suspended in $100 \mathrm{ml}$ of ethanol, ethyl acetate and water respectively in a sterile conical flask and kept at $4^{\circ} \mathrm{C}$ overnight. After incubation the supernatant was filtered through a whatman filter paper no.1 and the filterate was dried to evaporate the organic solvent at room temperature. The sedimented extract was 
weighed and dissolved in 5\% dimethyl sulphoxide.

\section{Nilavembu - Andrographis paniculata}

The leaves Andrographis paniculata were dried at room temperature and then crushed into a coarse powder using a blender. Fifty grams of powdered leaves of Andrographis paniculata were macerated with $100 \mathrm{ml}$ sterile distilled water in a blender for 10 minutes. The macerate was first filtered through double layered muslin cloth and centrifuged at $4000 \mathrm{~g}$ for 30 minutes. The supernatant was filtered through whatman No.1 filter paper and heat sterilized at $120 \mathrm{oC} 30$ minutes. The extract was preserved aseptically in a brown bottle at 4 oc until further use.

The fifty grams of plant extract was added with $300 \mathrm{ml}$ of ethanol, chloroform and water separately and kept for for 24 hours at $23 \mathrm{oC}$. The extract mixture was filtered with sterile whatman filter paper, collected in a clean conical flask. Second extraction was carried out with same amount of solvent for another 24 hours at $23 \mathrm{oC}$ and filtered. The extracts were later pooled and transferred into the sample holder of the rotary flash evaporator for the evaporation of solvents. The sedimented extract was weighed and dissolved in 5\% dimethylsulphoxide.

\section{Extract Preparation in Soxhelet Apparatus (Natarajan et al., 2003)}

To identify the compounds present in the sample with the suitable organic solvents system, by using soxhelet extraction method. The Plant extracts was loaded in the soxhelet apparatus, which could dissolve in the particular solvents (ethanol, ethyl acetate, and water - Azadirachta indica and ethanol, chloroform, and water Andrographis paniculata). Then the flask, soxhelet extractor glassware and water cooled condenser were assembled. The solvent was in the bottom flask. The solvent was allowed to boil using electric hot plate. The vapors directed through the extractor to the top mounted condenser. The condensed vapors drip down into the sample filling the extraction cup with solvent. In such a way the clean solvent vapors continuously allowed to condense refilled the soxhlet cup and flushed back into the flask. The cycling action extracted the compound soluble in the solvents, from the sample and collected to the flask. After cooling the flask, the solvent along with extract was condensed by evaporation and then used for further antimicrobial activity studies.

\section{Fungal Inoculum Preparation}

Out of the 115 samples, 64 isolates of Trichophyton mentagrophytes, 42 isolates of Trichophyton rubrum, 24 isolates of Trichophyton tonsurans, 37 isolates of Trichophyton terrestre, 20 isolates of Trichophyton verrucosum were isolated and identified. We have selected two most common pathogen among the Trichophyton species i.e., Trichophyton mentagrophytes and Trichophyton rubrum to find the antidermatophytic activity of Plant extracts. The organisms were grown on Sabouraud's dextrose agar plates. The 21 day old culture was scrapped with sterile scalpel and macerated in $10 \mathrm{ml}$ sterile water. The ground fungal suspension was adjusted spectrophotometrically to an absorbance of 0.600 at $450 \mathrm{~nm}$.

\section{Susceptibility Test (Radhika et al., 2013)}

One $\mathrm{ml}$ of the plant extract was incorporated into one $\mathrm{ml}$ of Sabouraud's dextrose broth and was serially diluted so as to achieve concentrations ranging from $1000 \mu \mathrm{g} / \mathrm{ml}$ to $31.25 \mu \mathrm{g} / \mathrm{ml}$ respectively. $20 \mu \mathrm{l}$ of fungal 
inoculum was added to each tube and incubated at room temperature for 21days. Suitable controls were included. Sabouraud's dextrose broth with $20 \mu$ of inoculum served as positive control whereas, SD broth alone served as negative control. The whole setup in duplicate was incubated at room temperature for 21 days.

\section{Minimum Inhibitory Concentration (MIC)}

To determine the combine activity of the plant extracts, and $0.5 \mathrm{ml}$ of each plant extract was added in the first tube of one $\mathrm{ml}$ of Sabouraud's dextrose broth gives the concentration of (each $500 \mathrm{ug}$ to give $1000 \mathrm{ug} / \mathrm{ml}$ ) and was serially diluted so as to achieve concentrations ranging from 1000 $\mu \mathrm{g} / \mathrm{ml}$ to $31.25 \mu \mathrm{g} / \mathrm{ml}$ respectively. Then $20 \mu 1$ of standard fungal inoculums was added to each tube and inoculated at room temperature for 21days. Suitable controls were included. Sabouraud's dextrose broth with $20 \mu \mathrm{l}$ of inoculum served as positive control whereas, SD broth alone served as negative control. The whole setup in duplicate was incubated at room temperature for 21 days. The MIC was regarded as the lowest concentration of the extract that did not permit any visible growth after 21 days of inoculums when compared with control.

\section{Minimum Fungicidal Concentration (MFC)}

The dilution in which the extract show no visible growth after 21 days of incubation was sub cultured on to SDA plates with an inoculums size of $1 \mathrm{ml}$.The MFC was regarded as lowest concentration that prevented the growth of any fungal colony in the solid medium.

\section{Result and Discussion}

Out of the 115 Soil samples, 64 isolates of Trichophyton mentagrophytes, 42 isolates of
Trichophyton rubrum, 24 isolates of Trichophyton tonsurans, 37 isolates of Trichophyton terrestre, 20 isolates of Trichophyton verrucosum were isolated and identified. It was shown in Graph-1. In Trichophyton species, T.mentagrophytes was inhibited by ethanolic extract of Azadirachta indica leaves in the concentration of $62.5(\mu \mathrm{g} / \mathrm{ml})$, whereas by Ethyl acetate extract in the concentration of $125(\mu \mathrm{g} / \mathrm{ml})$ and the aqueous extract in the concentration of $500(\mu \mathrm{g} / \mathrm{ml})$. The T.rubrum was inhibited by ethanolic extract in the concentration of $125(\mu \mathrm{g} / \mathrm{ml})$, whereas by ethyl acetate extract in the concentration of $250(\mu \mathrm{g} / \mathrm{ml})$ and the aqueous extract in the concentration of $500(\mu \mathrm{g} / \mathrm{ml})$. Ethanolic extract found to have higher activity than the ethyl acetate and the aqueous extract against both the organism T.mentagrophytes and T.rubrum. MIC and MFC of Azadirachta indica leaves extract against T.mentagrophytes and T.rubrum was shown Table-1 \& in Graph-2.In Trichophyton species, T.mentagrophytes was inhibited by ethanolic extract of Andrographis paniculata leaves extract in the concentration of $125(\mu \mathrm{g} / \mathrm{ml})$, whereas chloroform extract in the concentration of $250(\mu \mathrm{g} / \mathrm{ml})$ and the aqueous extract in the concentration of $1000(\mu \mathrm{g} / \mathrm{ml})$.

The T.rubrum was inhibited by ethanolic extract in the concentration of $62.5(\mu \mathrm{g} / \mathrm{ml})$, whereas by chloroform extract in the concentration of $125(\mu \mathrm{g} / \mathrm{ml})$ and the aqueous extract in the concentration of $500(\mu \mathrm{g} / \mathrm{ml})$. Ethanolic extract found to have higher activity than the chloroform and the aqueous extract against both the organism T.mentagrophytes and T.rubrum. MIC and MFC of Andrographis paniculata leaves extract against T.mentagrophytes and T.rubrum was shown Table- $2 \&$ in Graph-3. T.mentagrophytes and T.rubrum were inhibited by ethanolic extract of Azadirachta indica and Andrographis paniculata extract 
in the concentration of $62.5(\mu \mathrm{g} / \mathrm{ml})$, against T.mentagrophytes and $125(\mu \mathrm{g} / \mathrm{ml})$, against T.rubrum. Ethanolic extract of combination of plant have greater activity against T.mentagrophytes than T.rubrum was
Shown in graph-4. Leaves of Andrographis paniculata, Azadirachta indica and Hair baiting technique was shown in figure 1, 2 and 3 respectively.

Table.1 MIC \& MFC of Neem Leaves Extract

\begin{tabular}{|l|l|l|l|l|l|l|l|l|}
\hline S.No & Organism & \multirow{2}{*}{ Isolates } & \multicolumn{2}{l|}{$\begin{array}{l}\text { Ethanolic Extract } \\
(\boldsymbol{\mu g} / \mathbf{m l})\end{array}$} & \multicolumn{2}{l|}{$\begin{array}{l}\text { Ethylacetate } \\
\text { Extract }(\boldsymbol{\mu g} / \mathbf{m l})\end{array}$} & \multicolumn{2}{l|}{$\begin{array}{l}\text { Aqueous Extract } \\
(\boldsymbol{\mu} \text { /ml })\end{array}$} \\
\cline { 3 - 9 } & & & MIC100 & MFC100 & MIC100 & MFC100 & MIC100 & MFC100 \\
\hline 1 & T.mentagrophytes & 64 & 62.5 & 62.5 & 125 & 125 & 500 & 500 \\
\hline 2 & T.rubrum & 42 & 125 & 125 & 250 & 250 & 500 & 500 \\
\hline
\end{tabular}

Table.2 Shows the MIC\& MFC of Nilavembu Leaves Extract

\begin{tabular}{|l|l|l|l|l|l|l|l|l|}
\hline S.No & Organism & Isolates & \multicolumn{2}{l|}{$\begin{array}{l}\text { Ethanolic Extract } \\
(\boldsymbol{\mu g} / \mathbf{m l})\end{array}$} & \multicolumn{2}{l|}{$\begin{array}{l}\text { Chloroform } \\
\text { Extract } \\
(\boldsymbol{\mu g} / \mathbf{m l})\end{array}$} & & \multicolumn{2}{l|}{$\begin{array}{l}\text { Aqueous Extract } \\
(\boldsymbol{\mu g} / \mathbf{m l})\end{array}$} \\
\cline { 3 - 9 } & & & MIC100 & MFC100 & MIC100 & MFC100 & MIC100 & MFC100 \\
\hline 1 & T.mentagrophytes & 64 & 125 & 125 & 250 & 250 & 1000 & 1000 \\
\hline 2 & T.rubrum & 42 & 62.5 & 62.5 & 125 & 125 & 500 & 500 \\
\hline
\end{tabular}

Figure-1

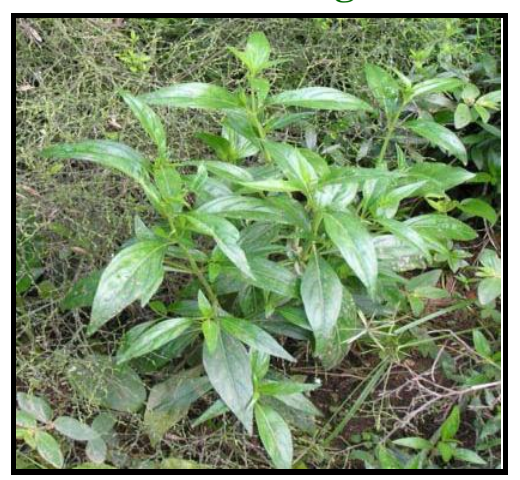

Figure-2

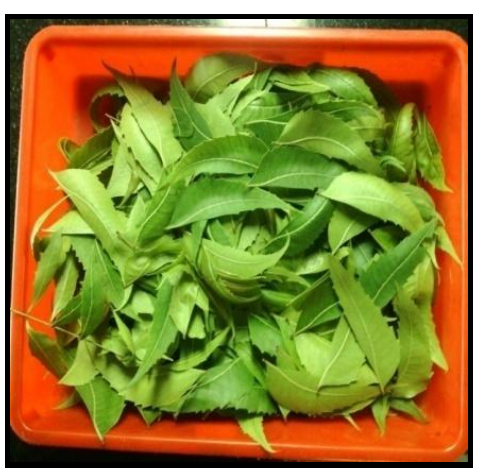

Figure-3

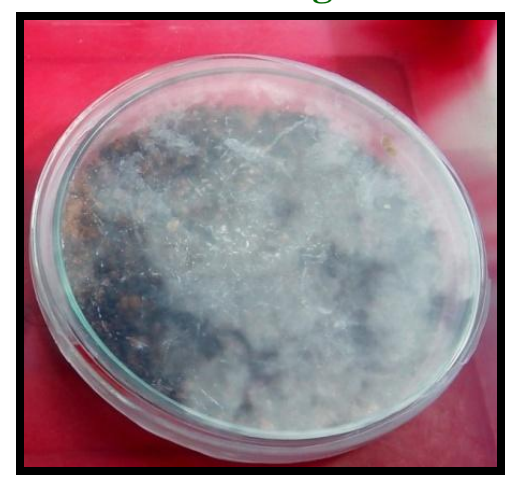

Graph.1 Shows the Isolates from the Soil Sample

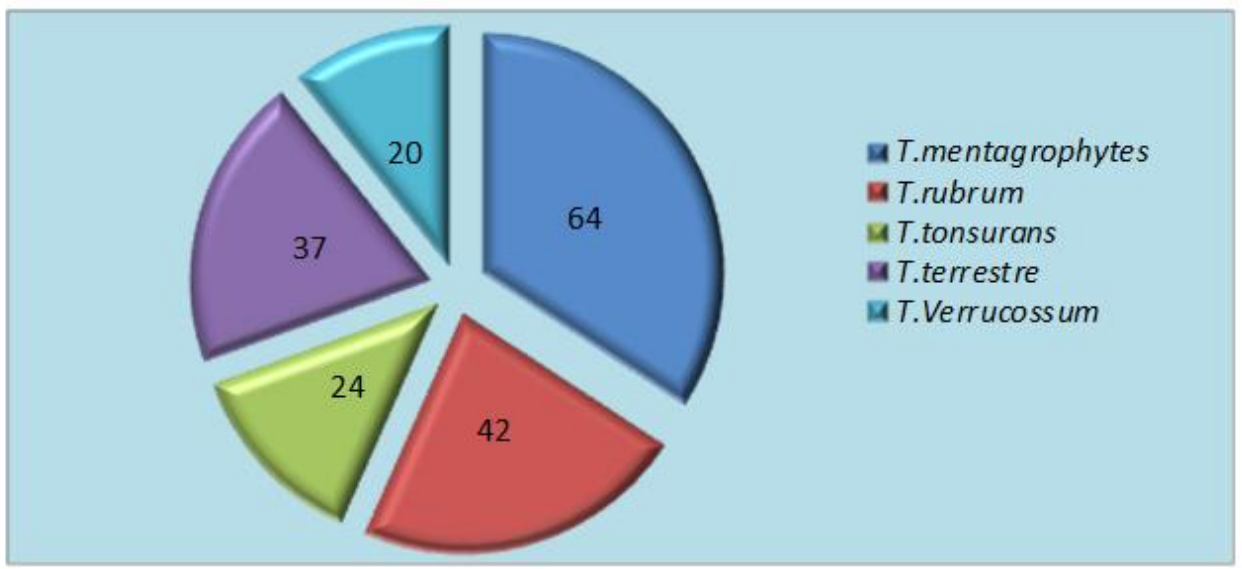


Graph.2 Shows the MIC of Neem Leaves Extract

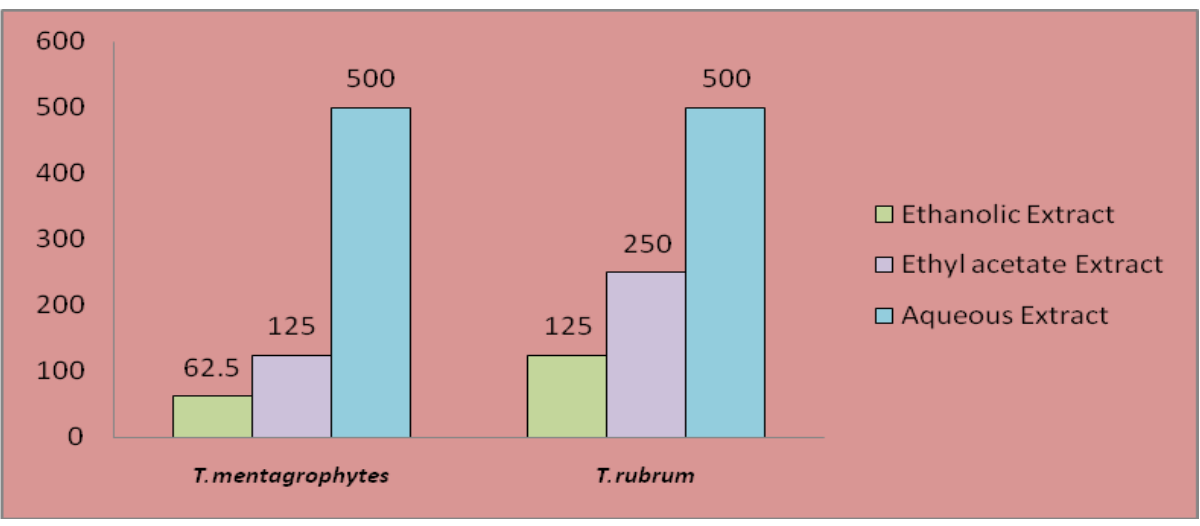

Graph.3 Shows the MIC of Nilavembu Leaves Extract

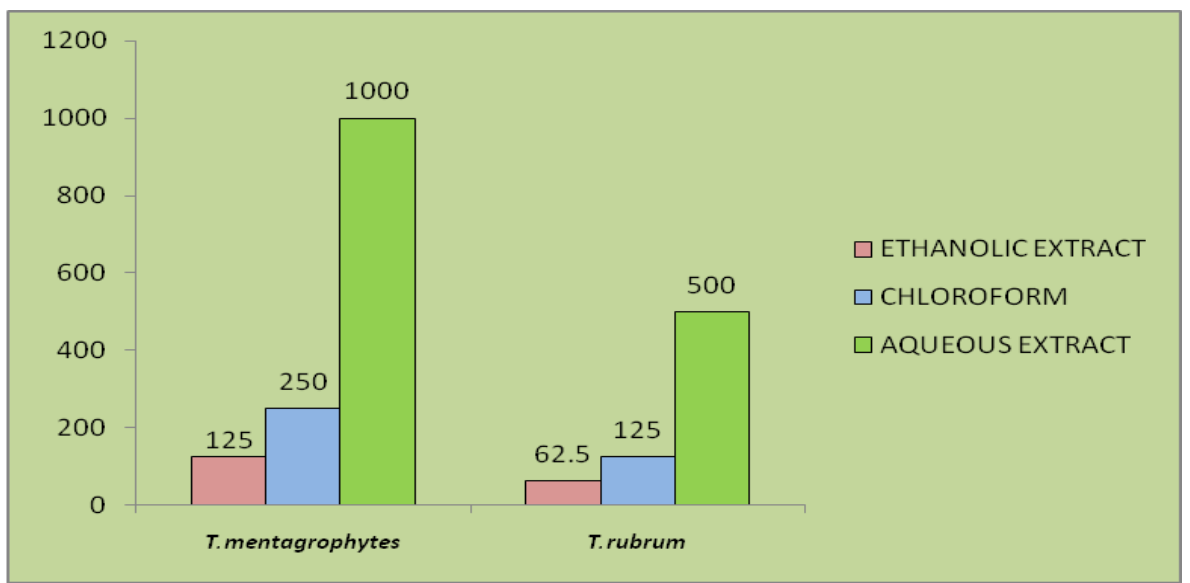

Graph.4 Shows the MIC of Nilavembu and Neem Extract with Ethanolic Extract

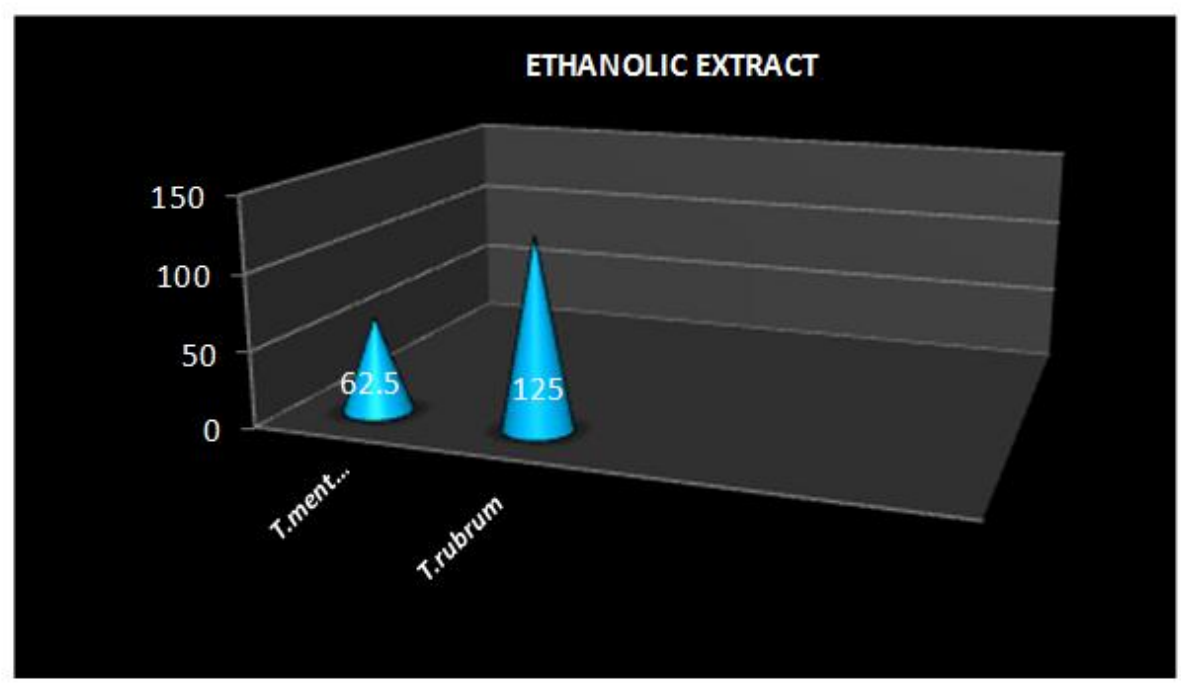


In vivo and in vitro antidermatophytic activity of Azadirachta indica was studied, Minimum inhibitory concentration of petroleum ether extract recorded for strains of Trichophyton rubrum, Trichophyton mentagrophytes, Trichophyton tonsurans, Microsporum nanum and Epidermophyton floccosum were above $1000 \mu \mathrm{g} / \mathrm{ml}$ and those of ethanolic and ethyl acetate extract of neem leaf ranged from $500-1000 \mu \mathrm{g} / \mathrm{ml}$ for Trichophyton mentagrophytes, Trichophyton rubrum and Trichophyton tonsurans. The extracts of Neem when used as medicinal plant, could be useful for the growth inhibition of the harmful fungus. The phytoconstituents alkaloids, glycosides, flavanoids and saponins are antibiotic principles of plants. These antibiotic principles are actually the defensive mechanism of the plants against different pathogens (Hafiza, 2000). The Drug development plant based compounds could be useful in meeting this demand for newer drugs with minimal side effects. In our study we selected two medicinal plant Nilavembu - Androgrphis paniculata and Neem Azadirachta indica which showed greater inhibitatory activity against Trichophyton Species. The ethanol extracts of Neem leaves showed MIC and MFC at 250 $(\mu \mathrm{g} / \mathrm{ml})$ concentration for all the strains of T.rubrum and M.nanum. MIC and MFC recorded for strains T.mentagrophytes was $125(\mu \mathrm{g} / \mathrm{ml})$ (Natarajan et al., 2003). Hydroalcoholic extracts of all the plants were found to have maximum antifungal activity in comparison to hexane extracts. Hydro-alcoholic extract of Andrographis paniculata possessed potent antifungal activity. The antifungal activity of seed extracts viz. leaf, stem and root were evaluated against five fungal sp. Stem extract of Andrographis paniculata showed significant antifungal activity against A. oryzae, Penicillium sp and C.albicans. Leaf extract of Azadirachta indica at different concentrations significantly suppressed the growth of the pathogenic fungi. The extracts of Azadirachta indica from bark and leaf, inhibited both spore germination and mycelia growth of Epidermophyton floccosum, Microsporum gypseum and Trichophyton mentagrophytes.

In conclusion, Plant extracts are being used for treatment of various diseases and are gaining importance as, the anticancer, antimalarial activity, analgesic and antiinflammatory activity, antibacterial, antiviral and antidermatophytic properties. Azadirachta indica and Andrographis paniculata leaves with different solvent system showed the antidermatophytic activity against the Trichophyton species. The combined activity of Azadirachta indica with Andrographis paniculata showed better inhibitory activity because of the synerism.

Therefore, in recent years, there has been growing interest in search of suitable medicinal plants for skin ailments. The numerous ethnic tribes in India have developed their own herbal remedies for all their diseases including the skin ailments. Therefore natural herbs are gaining importance in overcoming this problem as the traditional herbs are found to be more economical and having lesser side effects than synthestic drugs. In future the plant components are separated and subjected to phytochemical and pharmacological investigation.

\section{References}

Abhishek Mathur, Ravinder Singh, Sajad Yousuf, Aprajita Bhardwaj, Satish, K., Verma Pradeep Babu, Vinay Gupta, Prasad, G.B.K.S, Dua, V.K. 2011. Antifungal activity of some plant extracts against clinical pathogens. $A d v$. Appl. Sci. Res., 2(2): 260-264. 
Alireza, V., Mihdzar, A.K., Soon, G.T., Daryush, T., Mohd, P.A., Sonia, N. 2011. Nain-e Havandi Andrographis paniculata present yesterday, absent today: a plenary review on underutilized herb of Iran's pharmaceutical plants. Int. J. Mol. Cellular Biol., 39(5): 5409- 5424.

Banu Rekha, C., Krishnaveni, G., Rajendran, P. 2015. Prevalence of Trichophyton Species from Selected Soils of Chennai, India. Asian $J$. Multidisciplinary Studies, 3(12):126-31.

Bishnu Joshi, Govind Prasad Sah, Buddha Bahadur Basnet, Megh Raj Bhatt, Dinita Sharma, Krishna Subedi, Janardhan Pandey, Rajani Malla. 2011. Phytochemical extraction and antimicrobial propertiesof different medicinal plants: Ocimum sanctum (Tulsi), Eugenia caryophyllata (Clove), Achyranthes bidentata (Datiwan) and Azadirachta indica (Neem) $J$. Microbiol. Antimicrobials, 3(1): 1-7.

Chanda, S., Rakholiya, K. 2011. Combination therapy: Synergism between natural plant extracts and antibiotics against infectious diseases. Microbiol Book Series, 520-529.

Hafiza, R.E. 2000 Peptides antibiotics, Lancet, 349: 418-422.

Hossain, M.A., Nagooru, M.R. 2011. Biochemical profiling and total flavonoids contents of leaves crude extract of endemic medicinal plant Corydyline terminalis L. Kunth, Pharmacognosy J., 3: 25-30.

Imam Hashmat1, Hussain Azad, Ajij Ahmed. 2012. Neem (Azadirachta indica A. Juss) - A Nature's Drugstore: An overview. I. Res. J. Biological Sci., 1(6): 76-79.

Khosla, P., Sangeeta, B., Jain, K., Srivastva, R.K. 2000. Antinociceptive activity of Azadirachta indica(neem) in rats. Indian J. phamacol., 32: 372-374.
Manoharan Sivananthan. 2013. Pharmacological activities of Andrographis paniculata, Allium sativum and Adhatoda vasica Int. J. Biomolecules and Biomed., 3(2) : 1320.

Mohammad, A., Hossaina, Wafa, A.S., AlToubia, Afaf, M., Welia, Qasim, A., AlRiyamia, Jamal, N., Al-Sabahi. 2013. Identification and characterization of chemical compounds in different crude extracts from leaves of Omani neem. $J$. Taibah University for Sci., 7 : 181-188.

Meenu sharma, Aakanksha sharma, Sandeep Tyagi. 2012. Quantitative HPLC analysis of Andrographolide in Andrographis paniculata at two different stages of life cycle of plant Acta Chim. Pharm. Indica., 2(1): 1-7.

Munuswamy Hemalatha, Thirunavukkarasu Thirumalai, Rajamani Saranya, Erusan Kuppan Elumalai, Ernest David. 2013. A review on antimicrobial efficacy of some traditional medicinalplants in Tamilnadu. J. Acute Dis., 99-105.

Natarajan, V., Venugopal, P.V., Menon, T. 2003. Effect of Azadirachta indica (neem) on the growth pattern of dermatophytes. Indian J. Med. Microbiol., 21: 98-10.

Ranganathan, S., Thangam Menon, Arun Mozhi, S., Balajee, Mahendra, S., Raja. 1996. Antidermatophytic Activites of Azadirachta indica : An In Vitro And In Vivo Study. Int. J. Dermatol., 41 : 113-117.

Radhika, S.M., Michael, A. 2013. Invitro antifungal activity of leaf extracts of Azadirachta indica. Int. J. Pharm. Pharma. Sci., 5(4): 0975-1491.

Rajalakshmi, G.D., Aruna, B., Bhuvaneswari, R.S., Venkatesan, Natarajan, A., Jegatheesa, K. 2012. Prophylactic effect Andrographis paniculata extracts against fungal 
species. J. pharma. Appl. Sci., 2(9):058060.

Rajpar, I., Khanif, Y.M., Zia-ul-hassan, Shah, A.N., Arshad, M. 2011. Growth, herb yield and phytochemical contents in a medicinal herb Andrographis paniculata under saline irrigation. $J$. Med. Plants Res., 5(23): 5528-5533.

Ross, I.A. 2001. Medicinal plants of the world: Chemical constituents, Traditional and modern medicinal uses, Totowa, New Jersy, 2:81-85.
Susmitha, S., Vidyamol, $\quad$ K.K., Ranganayaki, P., Vijayaragavan, R. 2013. Phytochemical Extraction and Antimicrobial Properties of Azadirachta indica (Neem). Global $J$. Pharmacol., 7(3): 316-320.

Sukanya, S.L., Sudisha, J., Hariprasad, P., Niranjana, S.R., Prakash, H.S., Fathima, S.K. 2009. Antimicrobial activity of leaf extracts of Indian medicinal plants against clinical and Phytopathogenic bacteria. Afr. J. Bio., 8(23): 6677- 6682.

\section{How to cite this article:}

Banu Rekha, C., G. Krishnaveni, P. Rajendran, Ramya Anandan and Elakkiya, M. 2016. In Vitro Antidermatophytic Study on Leaf Extracts of Azadirachta indica and Andrographis paniculata against Trichophyton Species. Int.J.Curr.Microbiol.App.Sci. 5(5): 636-646. doi: http://dx.doi.org/10.20546/ijcmas.2016.505.064 